\title{
Synthesis, structure and properties of $\mathrm{Pb}_{2} \mathrm{CuB}_{2} \mathrm{O}_{6}$
}

\author{
Shilie Pan ${ }^{\text {a }}$, Jared P. Smit ${ }^{\mathrm{a}}$, Michael R. Marvel ${ }^{\mathrm{a}}$, \\ Charlotte L. Stern ${ }^{a}$, Byron Watkins ${ }^{b}$, Kenneth R. Poeppelmeier ${ }^{a, *}$ \\ ${ }^{a}$ Department of Chemistry, Northwestern University, 2145 Sheridan Road, \\ Evanston, IL 60208-3133, United States \\ ${ }^{\mathrm{b}}$ Department of Physics and Astronomy, Northwestern University, 2145 Sheridan Road, \\ Evanston, IL 60208-3112, United States
}

Received 7 December 2005; accepted 23 December 2005

Available online 26 January 2006

\begin{abstract}
Single crystals of $\mathrm{Pb}_{2} \mathrm{CuB}_{2} \mathrm{O}_{6}$ were grown from a $\mathrm{PbO} / \mathrm{CuO} / \mathrm{B}_{2} \mathrm{O}_{3}$ flux, and crystallize in a monoclinic cell of dimensions $a=5.6311(6), b=8.7628(9), c=6.2025(6) \AA$, and $\beta=115.7060(10)^{\circ}$ with $Z=2$; the space group is $P 2{ }_{1} / c$ (no. 14). The structure was determined from 662 unique reflections and refined to the final residuals $R_{1}=0.0217, w R_{2}=0.0586$. The structure is characterized by the two-dimensional layer of interconnected rectangular planar $\mathrm{CuO}_{4}$ and triangular planar $\mathrm{BO}_{3}$ groups. The results of quantitative analysis ICP, DTA, vibrational spectroscopy, and magnetic investigations are also presented.
\end{abstract}

(C) 2006 Elsevier Ltd. All rights reserved.

Keywords: C. X-ray diffraction; A. Oxide; B. Crystal growth; D. Crystal structure; D. Magnetic properties

\section{Introduction}

One of the primary goals of chemistry is the development and creation of new materials, and the growth of single crystals from oxide fluxes is a good way to facilitate the discovery of new compounds. Synthesis of complex oxides and the improvement of existing technologies for the production of these materials are based on the fundamental investigations into the relationship between composition, structure, and properties.

Owing to their potentially interesting properties, complex oxides such as cuprates and borates are of interest. For example, cuprate compounds such as $\mathrm{SrCu}_{2} \mathrm{O}_{3}$ [1,2], $\mathrm{Sr}_{14} \mathrm{Cu}_{24} \mathrm{O}_{41}$ [3], and $\mathrm{La}_{4} \mathrm{Cu}_{3} \mathrm{MoO}_{12}$ [4,5] have attracted attention because of their unusual low-temperature magnetic properties. Cuprate and borate groups are two-dimensional spin gap systems with the exact dimer ground state [6-8]. Additionally, several borate phases display excellent linear and non-linear optical properties [9-16]. The combination of cuprate and borate groups in the same compound may generate a new class of interesting materials as the ternary $\mathrm{PbO}-\mathrm{CuO}-\mathrm{B}_{2} \mathrm{O}_{3}$ system has been studied very little [17]. In this report, the synthesis, crystal structure, DTA, vibrational spectroscopy, and magnetic properties of $\mathrm{Pb}_{2} \mathrm{CuB}_{2} \mathrm{O}_{6}$ are described, which is the first of a new family of lead copper borates in the ternary system $\mathrm{PbO}-\mathrm{CuO}-\mathrm{B}_{2} \mathrm{O}_{3}$ that have been discovered.

\footnotetext{
* Corresponding author. Tel.: +1 847491 3505; fax: +1 8474917713 .

E-mail address: krp@northwestern.edu (K.R. Poeppelmeier).
} 


\section{Experimental}

\subsection{Polycrystalline synthesis}

A polycrystalline sample of $\mathrm{Pb}_{2} \mathrm{CuB}_{2} \mathrm{O}_{6}$ was prepared by standard solid-state reaction method using $\mathrm{PbO}$ (99.99\%, Alfa-Aesar), $\mathrm{CuO}$ (99.995\%, Alfa-Aesar), and $\mathrm{B}_{2} \mathrm{O}_{3}$ (99.98\%, Sigma-Aldrich) as the starting components in the molar ratio 2:1:1. The reagents were mixed, ground in an agate mortar, and packed into a platinum crucible. The mixture was heated to $773 \mathrm{~K}$ in air for $24 \mathrm{~h}$ (with occasional grinding), and then sintered at $923 \mathrm{~K}$ for an additional $24 \mathrm{~h}$. The sample purity was verified by X-ray powder diffraction. The chemical equation can be expressed as follows:

$$
2 \mathrm{PbO}+\mathrm{CuO}+\mathrm{B}_{2} \mathrm{O}_{3} \rightarrow \mathrm{Pb}_{2} \mathrm{CuB}_{2} \mathrm{O}_{6}
$$

\subsection{Single crystal synthesis}

A $30 \mathrm{~g}$ polycrystalline sample was melted in a platinum crucible at $1173 \mathrm{~K}$, and kept at $1173 \mathrm{~K}$ for $8 \mathrm{~h}$. The furnace was slowly cooled to $953 \mathrm{~K}$ at a rate of $0.1 \mathrm{~K} / \mathrm{min}$, and then cooled to room temperature at a rate of 20-30 K/h. Dark green needle-like crystals were separated from the crucible for the structure determination.

\subsection{Large single crystal growth}

In order to obtain crystals for property measurements, crystal growth was carried out in a vertical Molysili furnace. The polycrystalline sample with $120 \mathrm{~g}$ was melted in a platinum crucible at $1173 \mathrm{~K}$, kept at $1173 \mathrm{~K}$ for $12 \mathrm{~h}$. A platinum wire was dipped into the solution and the furnace was slowly cooled to $953 \mathrm{~K}$ at a rate of $0.3 \mathrm{~K} / \mathrm{h}$. The sample was then cooled down to room temperature at a rate of $20-30 \mathrm{~K} / \mathrm{h}$. The crystals were cracked, but parts of them were transparent and useful for the properties measurement.

\subsection{X-ray powder diffraction}

X-ray powder diffraction analysis of $\mathrm{Pb}_{2} \mathrm{CuB}_{2} \mathrm{O}_{6}$ was performed at room temperature in the angular range of $2 \theta=10-70^{\circ}$ with a scan step width of $0.02^{\circ}$ and a fixed counting time of $1 \mathrm{~s} / \mathrm{step}$ using an automated Rigaku X-ray diffractometer equipped with a diffracted-beamed monochromator set for $\mathrm{Cu} K \alpha(\lambda=1.5418 \AA)$ radiation. The X-ray powder diffraction patterns of both the synthesized and calculated $\mathrm{Pb}_{2} \mathrm{Cu}\left(\mathrm{BO}_{3}\right)_{2}$ are identical (Fig. 1), indicating that the synthesized phase contains no other phases.

\subsection{X-ray crystallography}

A needle-shaped blue single crystal of $\mathrm{Pb}_{2} \mathrm{CuB}_{2} \mathrm{O}_{6}$ with dimensions $0.02 \mathrm{~mm} \times 0.02 \mathrm{~mm} \times 0.70 \mathrm{~mm}$ was chosen for the structure determination. Unit cell parameters were derived from a least-squares analysis of 2418 reflections in

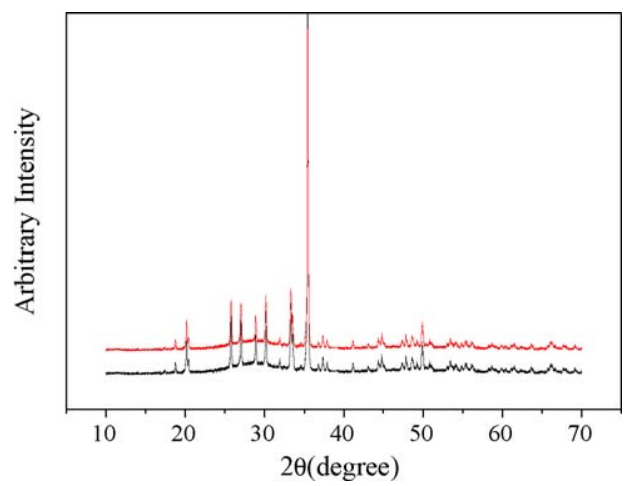

Fig. 1. X-ray powder diffraction patterns of both the synthesized and calculated $\mathrm{Pb}_{2} \mathrm{CuB}_{2} \mathrm{O}_{6}$. The red curve is its calculated pattern, the black one is its synthesized pattern. 
Table 1

Crystal data and structure refinement for $\mathrm{Pb}_{2} \mathrm{CuB}_{2} \mathrm{O}_{6}$

\begin{tabular}{|c|c|}
\hline Empirical formula & $\mathrm{Pb}_{2} \mathrm{CuB}_{2} \mathrm{O}_{6}$ \\
\hline Formula weight & 595.54 \\
\hline Temperature (K) & $153(2)$ \\
\hline Crystal system & Monoclinic \\
\hline Space group & $P 2_{1} / \mathrm{c}$ \\
\hline Unit cell dimensions & $\begin{array}{l}a=5.6311(6) \AA, \alpha=90^{\circ} \\
b=8.7628(9) \AA, \beta=115.7060(10)^{\circ} \\
c=6.2025(6) \AA, \gamma=90^{\circ}\end{array}$ \\
\hline Volume $\left(\AA^{3}\right)$ & $275.77(5)$ \\
\hline$Z$ & 2 \\
\hline Density (calculated; $\mathrm{g} / \mathrm{cm}^{3}$ ) & 7.172 \\
\hline Absorption coefficient $\left(\mathrm{mm}^{-1}\right)$ & 64.684 \\
\hline$F\left(\begin{array}{lll}0 & 0 & 0\end{array}\right)$ & 502 \\
\hline Theta range for data collection $\left({ }^{\circ}\right)$ & $4.02-28.54$ \\
\hline Index ranges & $-7 \leq h \geq 7,-11 \leq k \geq 11,-8 \leq l \geq 8$ \\
\hline Reflections collected & 2418 \\
\hline Independent reflections & $662[R(\mathrm{int})=0.0329]$ \\
\hline Completeness to $\theta=27.19$ & $94.2 \%$ \\
\hline Maximum and minimum transmission & 0.3219 and 0.2172 \\
\hline Data/restraints/parameters & $662 / 0 / 53$ \\
\hline Goodness-of-fit on $F^{2}$ & 1.117 \\
\hline Final $R$ indices $\left[F_{0}^{2}>2 \sigma\left(F_{0}^{2}\right)\right]^{\mathrm{a}}$ & $R_{1}=0.0217, w R_{2}=0.0586$ \\
\hline$R$ indices (all data) & $R_{1}=0.0226, w R_{2}=0.0591$ \\
\hline Extinction coefficient & $0.0016(5)$ \\
\hline Largest diffraction peak and hole $\left(\mathrm{e} . \AA^{-3}\right)$ & 2.19 and -2.2 \\
\hline
\end{tabular}

${ }^{\mathrm{a}} R_{1}=\Sigma|| F_{0}|-| F_{\mathrm{c}}|| \Sigma\left|F_{0}\right|$ and $w R_{2}=\left[\sum w\left(F_{0}^{2}-F_{\mathrm{c}}^{2}\right)^{2} / \sum w F_{0}^{4}\right]^{1 / 2}$ for $F_{0}^{2}>2 \sigma\left(F_{0}^{2}\right)$ and $w^{-1}=\sigma^{2}\left(F_{0}^{2}\right)+(0.035 P)^{2}+1.3590 P$ where $P=\left(F_{0}^{2}+2 F_{\mathrm{c}}^{2}\right) / 3$.

the range $4.02^{\circ}<\theta<28.54^{\circ}$ on a Bruker SMART - 1000 CCD diffractometer using monochromatic Mo K $\alpha$ radiation $(\lambda=0.71073 \AA)$ and integrated with the SAINT - Plus program [18].

All calculations were performed with programs from the SHELXTL crystallographic software package [19]. The systematic absences $h 0 l, l=2 n+1$, and $0 k 0, k=2 n+1$ unambiguously define the space group $P 2_{1} / c$ for the compound $\mathrm{Pb}_{2} \mathrm{CuB}_{2} \mathrm{O}_{6}$. The positional parameters for the $\mathrm{Pb}$ and $\mathrm{Cu}$ atoms were determined from the direct methods with the remaining atomic positions determined from analysis of subsequent difference electron density syntheses. A face-indexed absorption correction was performed numerically using the XPREP program, followed by the SADABS program [20]; equivalent reflections were then averaged. Final least-squares refinement on $F_{0}^{2}$ with data having $F_{0}^{2} \geq 2 \sigma\left(F_{0}^{2}\right)$ includes anisotropic displacement parameters for all atoms. The final difference Fourier synthesis may have shown maximum and minimum peaks at $2.19\left(1.08 \AA\right.$ from $\left.\mathrm{Pb}_{1}\right)$ and $-2.26 \mathrm{e} . \AA^{-3}\left(0.82 \AA\right.$ from $\left.\mathrm{Pb}_{1}\right)$, respectively. Additional crystal data and experimental conditions are summarized in Table 1.

\subsection{Quantitative analysis}

The composition of the new compound $\mathrm{Pb}_{2} \mathrm{CuB}_{2} \mathrm{O}_{6}$, with respect to the elements lead, copper, and boron, was verified using ICP on a VISTA-MPX Spectrometer.

\subsection{Vibrational spectroscopy}

IR spectroscopy was carried out with the objective of specifying and comparing the coordination of boron in $\mathrm{Pb}_{2} \mathrm{CuB}_{2} \mathrm{O}_{6}$. Its mid-infrared spectrum was obtained at room temperature via a Bio-Rad FTS-60 FTIR spectrometer. The sample was thoroughly mixed with dried $\mathrm{KBr}$ ( $5 \mathrm{mg}$ of the sample, $450 \mathrm{mg}$ of $\mathrm{KBr}$ ). The spectrum was collected in a range from 400 to $4000 \mathrm{~cm}^{-1}$ with a resolution of $2 \mathrm{~cm}^{-1}$. At least two spectra for each sample were recorded. Infrared spectra were corrected for the dark current noises and background using the two-point baseline correction. 
Table 2

Atomic coordinates $\left(\times 10^{4}\right)$ and equivalent isotropic displacement parameters $\left(\AA^{2} \times 10^{3}\right)$ for $\mathrm{Pb}_{2} \mathrm{CuB}_{2} \mathrm{O}_{6}$

\begin{tabular}{lllrr}
\hline Atom & $x$ & $y$ & $z$ & $U_{\text {eq }}$ \\
\hline $\mathrm{Pb}(1)$ & $8026(1)$ & $1075(1)$ & $1575(1)$ & 0 \\
$\mathrm{Cu} \mathrm{(1)}$ & 5000 & 5000 & $6(1)$ \\
$\mathrm{B}(1)$ & $2612(15)$ & $2508(8)$ & $-3430(12)$ & $6(1)$ \\
$\mathrm{O}(1)$ & $208(10)$ & $3227(5)$ & $860(8)$ & $6(1)$ \\
$\mathrm{O}(2)$ & $4855(10)$ & $3207(5)$ & $1789(8)$ & $8(1)$ \\
$\mathrm{O}(3)$ & $2572(10)$ & $4056(5)$ & $-2939(9)$ & $9(1)$ \\
\hline
\end{tabular}

$U_{\text {eq }}$ is defined as one-third of the trace of the orthogonalized $U_{i j}$ tensor.

Each spectrum was normalized by making its absorption vary from zero to one arbitrary unit. Such normalization was necessary to eliminate the concentration effect of the powder sample in the $\mathrm{KBr}$ disc.

\subsubsection{Thermoanalytical investigations}

Thermal stability of $\mathrm{Pb}_{2} \mathrm{CuB}_{2} \mathrm{O}_{6}$ was examined under static air with a differential thermal analyzer 1600-2910 DSC. The sample and reference $\left(\mathrm{Al}_{2} \mathrm{O}_{3}\right)$ were enclosed in Pt crucibles, heated, and then cooled at a rate of $10 \mathrm{~K} / \mathrm{min}$.

\subsubsection{Magnetic susceptibility}

The temperature dependence of the magnetic moment for the polycrystalline, powdered sample of $\mathrm{Pb}_{2} \mathrm{CuB}_{2} \mathrm{O}_{6}$ was determined on a Quantum Design MPMS5 Superconducting Quantum Interference Device (SQUID) magnetometer in the temperature range 2-300 K. A quantity of $240 \mathrm{mg}$ was enclosed in a cellulose capsule, inserted into a transparent plastic tube, and attached to the sample holder rod. The sample was field cooled (FC) in 500 Oe and zero field cooled (ZFC) before 500 Oe field was applied; in each case the magnetic moment of the sample was measured as the sample was warmed to $300 \mathrm{~K}$. The molar susceptibility for both data sets was obtained by multiplying the magnetic moments by the formula weight (595.54) and dividing by the applied field (500 Oe) and the sample mass ( $240 \mathrm{mg}$ ). These two sets of data were compared for evidence of magnetic order. Additionally, these data were fitted to the Curie-Weiss law so that magnetic parameters could be extracted.

\section{Results and discussion}

\subsection{Crystal structure of $\mathrm{Pb}_{2} \mathrm{CuB}_{2} \mathrm{O}_{6}$}

Final atomic coordinates of the title compound are listed in Table 2. Selected interatomic distances and angles are given in Table 3.

The structure consists of rectangular planar $\mathrm{CuO}_{4}$ units, trigonal-planar $\mathrm{BO}_{3}$ groups, and polyhedral $\mathrm{PbO}_{7}$ units. Fig. 2 displays the structural connectivity along each of the crystallographic axes. The structure is characterized by the two-dimensional layer of interconnected rectangular planar $\mathrm{CuO}_{4}$ and triangular planar $\mathrm{BO}_{3}$ groups as shown in Fig. 2a (view along $a$ axis). These layers extend parallel to the $b-c$ plane and the structure is completed by joining successive layers by interleaving $\mathrm{Pb}$ atoms. The $\mathrm{CuO}_{4}$ rectangular planes of the sheet are rotated around the $\mathrm{O}(2)-\mathrm{Cu}-$ $\mathrm{O}(2)$ axes out of the $b-c$ plane, forming a herringbone pattern when viewed along the $c$-axis (Fig. 2b). The $\mathrm{B}$ atoms bridge the isolated planar $\mathrm{CuO}_{4}$ groups.

The $\mathrm{Pb}-\mathrm{O}$ distances vary from $2.395(5)$ to $2.894(4) \AA$ with an average value of 2.699(5) $\AA$. Four of the bond lengths are typical of average $\mathrm{Pb}-\mathrm{O}$ bond lengths [21,22], while the other three bonds are longer than expected (from $2.769(5)$ to $2.894(4) \AA$ ). If these three longer distances are considered to be a weak-bonding interaction, then the coordination environment around $\mathrm{Pb}$ should be described as a distorted seven coordinate polyhedron. The average $\mathrm{Cu}-\mathrm{O}$ distance of 1.937(5) $\AA$ is similar to values observed in other copper borates, e.g., 1.939(3) $\AA$ for $\mathrm{Ba}_{2} \mathrm{Cu}\left(\mathrm{BO}_{3}\right)_{2}$ [23] and 1.95(1) $\AA$ for $\mathrm{Cu}_{3} \mathrm{~B}_{2} \mathrm{O}_{6}$ [24]. The $\mathrm{BO}_{3}$ groups are quite regular. The average $\mathrm{B}-\mathrm{O}$ distance, 1.382(9) $\AA$, is similar to interactions observed in a variety of other simple borates [25-27]. All $\mathrm{O}$ atoms are bonded to four cations (see Table 4). 
Table 3

Selected bond distances $(\AA)$ and angles $\left(^{\circ}\right)$ for $\mathrm{Pb}_{2} \mathrm{CuB}_{2} \mathrm{O}_{6}$

\begin{tabular}{lrrr}
\hline $\mathrm{Pb}(1)-\mathrm{O}(1)$ & $2.395(5)$ & $\mathrm{O}(1)-\mathrm{Pb}(1)-\mathrm{O}(3) \# 1$ & $57.76(16)$ \\
$\mathrm{Pb}(1)-\mathrm{O}(3) \# 1$ & $2.447(5)$ & $\mathrm{O}(1)-\mathrm{Pb}(1)-\mathrm{O}(1) \# 2$ & $87.05(12)$ \\
$\mathrm{Pb}(1)-\mathrm{O}(1) \# 2$ & $2.473(5)$ & $\mathrm{O}(3) \# 1-\mathrm{Pb}(1)-\mathrm{O}(1) \# 2$ & $82.74(17)$ \\
$\mathrm{Pb}(1)-\mathrm{O}(2)$ & $2.628(5)$ & $\mathrm{O}(1)-\mathrm{Pb}(1)-\mathrm{O}(2)$ & $82.17(16)$ \\
$\mathrm{Pb}(1)-\mathrm{O}(3) \# 3$ & $2.769(5)$ & $\mathrm{O}(3) \# 1-\mathrm{Pb}(1)-\mathrm{O}(2)$ & $136.45(14)$ \\
$\mathrm{Pb}(1)-\mathrm{O}(2) \# 4$ & $2.792(5)$ & $\mathrm{O}(1) \# 2-\mathrm{Pb}(1)-\mathrm{O}(2)$ & $78.54(14)$ \\
$\mathrm{Pb}(1)-\mathrm{O}(1) \# 5$ & $2.894(4)$ & $\mathrm{O}(1)-\mathrm{Pb}(1)-\mathrm{O}(3) \# 3$ & $104.08(15)$ \\
$\mathrm{Cu}(1)-\mathrm{O}(3)$ & $1.927(5)$ & $\mathrm{O}(3) \# 1-\mathrm{Pb}(1)-\mathrm{O}(3) \# 3$ & $79.73(16)$ \\
$\mathrm{Cu}(1)-\mathrm{O}(3) \# 4$ & $1.927(5)$ & $\mathrm{O}(1) \# 2-\mathrm{Pb}(1)-\mathrm{O}(3) \# 3$ & $149.50(15)$ \\
$\mathrm{Cu}(1)-\mathrm{O}(2)$ & $1.946(5)$ & $\mathrm{O}(2)-\mathrm{Pb}(1)-\mathrm{O}(3) \# 3$ & $130.55(14)$ \\
$\mathrm{Cu}(1)-\mathrm{O}(2) \# 4$ & $1.946(5)$ & $\mathrm{O}(1)-\mathrm{Pb}(1)-\mathrm{O}(2) \# 4$ & $76.62(15)$ \\
$\mathrm{B}(1)-\mathrm{O}(2) \# 5$ & $1.363(9)$ & $\mathrm{O}(3) \# 1-\mathrm{Pb}(1)-\mathrm{O}(2) \# 4$ & $107.11(16)$ \\
$\mathrm{B}(1)-\mathrm{O}(1) \# 6$ & $1.387(9)$ & $\mathrm{O}(1) \# 2-\mathrm{Pb}(1)-\mathrm{O}(2) \# 4$ & $151.30(14)$ \\
$\mathrm{B}(1)-\mathrm{O}(3)$ & $1.393(9)$ & $\mathrm{O}(2)-\mathrm{Pb}(1)-\mathrm{O}(2) \# 4$ & $76.00(12)$ \\
$\mathrm{O}(3) \# 4-\mathrm{Cu}(1)-\mathrm{O}(2) \# 4$ & $\mathrm{O}(3) \# 3-\mathrm{Pb}(1)-\mathrm{O}(2) \# 4$ & \\
$\mathrm{O}(2)-\mathrm{Cu}(1)-\mathrm{O}(2) \# 4$ & $90.28(19)$ & $\mathrm{O}(3)-\mathrm{Cu}(1)-\mathrm{O}(3) \# 4$ & \\
$\mathrm{O}(2) \# 5-\mathrm{B}(1)-\mathrm{O}(1) \# 6$ & $180.0(16)$ & $\mathrm{O}(3)-\mathrm{Cu}(1)-\mathrm{O}(2)$ & \\
$\mathrm{O}(2) \# 5-\mathrm{B}(1)-\mathrm{O}(3)$ & $123.6(6)$ & $\mathrm{O}(3) \# 4-\mathrm{Cu}(1)-\mathrm{O}(2)$ & \\
$\mathrm{O}(1) \# 6-\mathrm{B}(1)-\mathrm{O}(3)$ & $121.9(6)$ & $\mathrm{O}(3)-\mathrm{Cu}(1)-\mathrm{O}(2) \# 4$ & \\
\hline
\end{tabular}

Note. Symmetry transformations used to generate equivalent atoms: \#1 $x+1,-y+1 / 2, z+1 / 2 ; \# 2 x,-y+1 / 2, z+1 / 2 ; \# 3-x+1,-y,-z ; \# 4$ $-x+1,-y+1,-z ; \# 5 x,-y+1 / 2, z-1 / 2 ; \# 6 x-1,-y+1 / 2, z-1 / 2$.

For further clarification, the bond valence sums of each atom in the compound $\mathrm{Pb}_{2} \mathrm{CuB}_{2} \mathrm{O}_{6}$ are calculated $[28,29]$ and listed in Table 4 . These charges, based on the bond lengths determined by the X-ray structure analysis, are in agreement with the expected oxidation states.

\section{Composition}

The quantitative analysis on a sample of $\mathrm{Pb}_{2} \mathrm{CuB}_{2} \mathrm{O}_{6}$ using ICP confirms the composition of the new lead copper borate based on the crystal structure solution (theoretical: $69.6 \% \mathrm{~Pb}, 10.7 \% \mathrm{Cu}, 3.6 \% \mathrm{~B}$; experimental: $65.1 \% \mathrm{~Pb}$, $10.6 \% \mathrm{Cu}, 3.7 \% \mathrm{~B})$.

\subsection{Thermal behavior of $\mathrm{Pb}_{2} \mathrm{CuB}_{2} \mathrm{O}_{6}$}

Samples were heated at $10 \mathrm{~K} / \mathrm{min}$ to $1173{ }^{\circ} \mathrm{C}$ on the DTA; there is a strong signal only at $968 \mathrm{~K}$ (Fig. 3), which implies that the $\mathrm{Pb}_{2} \mathrm{CuB}_{2} \mathrm{O}_{6}$ melts congruently. In order to further verify that $\mathrm{Pb}_{2} \mathrm{CuB}_{2} \mathrm{O}_{6}$ melts congruently, $2 \mathrm{~g}$ of $\mathrm{Pb}_{2} \mathrm{CuB}_{2} \mathrm{O}_{6}$ powder was heated to $1173 \mathrm{~K}$, and rapidly cooled to room temperature. Analysis of the X-ray powder diffraction pattern of the melt revealed only the peaks attributable to $\mathrm{Pb}_{2} \mathrm{CuB}_{2} \mathrm{O}_{6}$, which further demonstrates that $\mathrm{Pb}_{2} \mathrm{CuB}_{2} \mathrm{O}_{6}$ is a congruently melting compound. No weight loss could be observed in thermogravimetrical measurement between room temperature and $1173 \mathrm{~K}$.

\subsection{Vibrational spectroscopic characterization}

Fig. 4 shows the section from 400 to $4000 \mathrm{~cm}^{-1}$ of the infrared spectrum of $\mathrm{Pb}_{2} \mathrm{CuB}_{2} \mathrm{O}_{6}$. The observed frequencies between the 1150 and $1400 \mathrm{~cm}^{-1}$ correspond to the stretching frequencies of coordinated $\mathrm{BO}_{3}$ groups and the absorption peaks below $810 \mathrm{~cm}^{-1}$, are typical for triangular $\mathrm{BO}_{3}$ groups [30-32].

\subsection{Magnetic susceptibility}

The magnetic susceptibility and inverse susceptibility of $\mathrm{Pb}_{2} \mathrm{CuB}_{2} \mathrm{O}_{6}$ as a function of temperature is plotted in Fig. 5. In this figure, the susceptibility has been defined as the ratio of the magnetization $M$ to the applied field $H$ $(\chi=M / H)$. As shown in Fig. 5, the overall shape of the magnetic susceptibility curve from 2 to $300 \mathrm{~K}$ indicated paramagnetic behavior $\chi(T)=C /(T-\theta)$. The fitting parameters found are the Curie constant, 

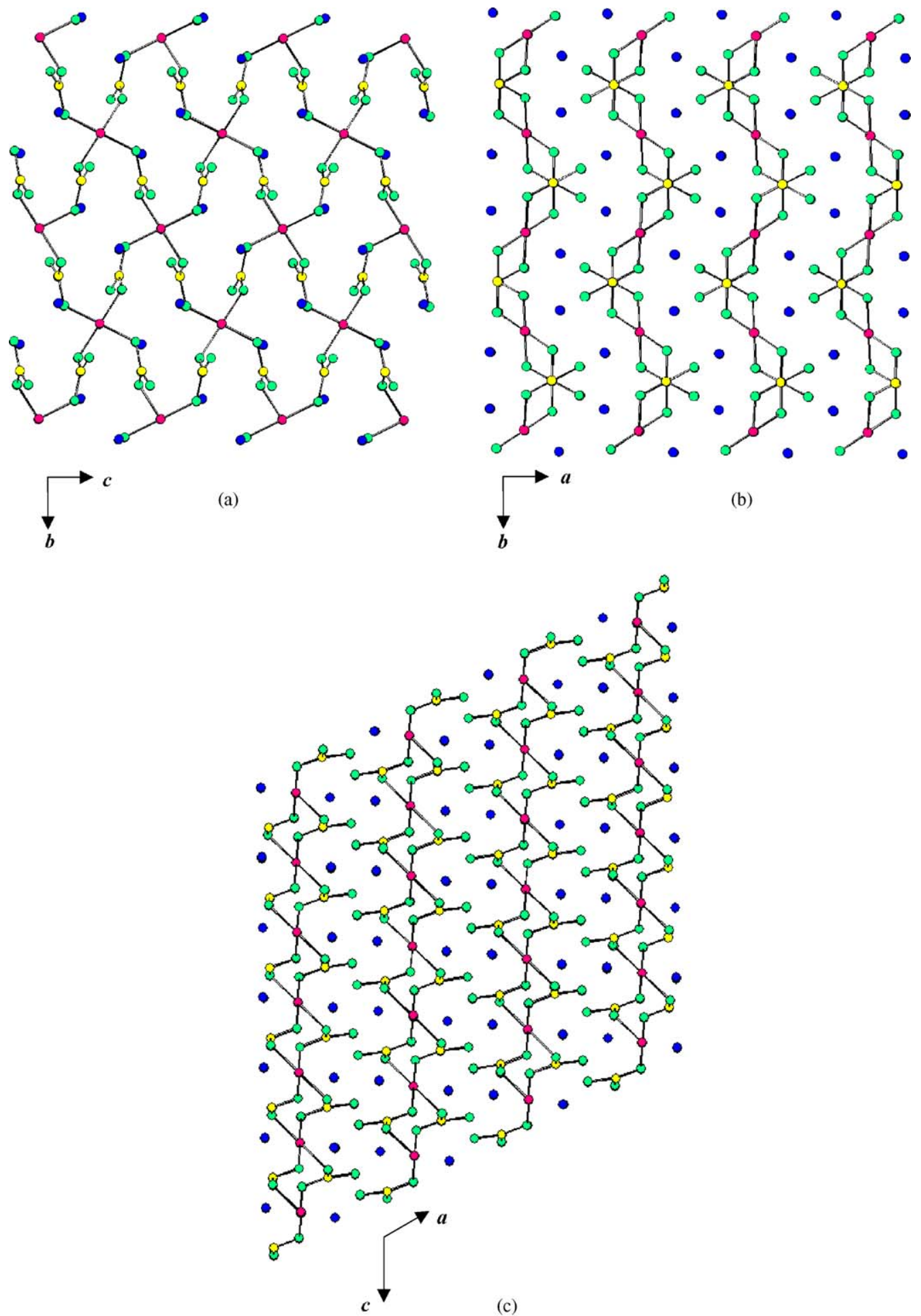

Fig. 2. The structural connectivity along each of the crystallographic axes. The blue balls are $\mathrm{Pb}$, the red balls are $\mathrm{Cu}$, the yellow balls are $\mathrm{B}$, the green balls represent $\mathrm{O}$ atoms. (a) Layer of interconnected rectangular planar $\mathrm{CuO}_{4}$ and triangular planar $\mathrm{BO}_{3}$ groups viewed along the $a$-axis. (b) Crystal structure of $\mathrm{Pb}_{2} \mathrm{CuB}_{2} \mathrm{O}_{6}$ viewed along the $c$-axis. (c) Crystal structure of $\mathrm{Pb}_{2} \mathrm{CuB}_{2} \mathrm{O}_{6}$ viewed along the $b$-axis. 
Table 4

Bond valence analysis of the $\mathrm{Pb}_{2} \mathrm{CuB}_{2} \mathrm{O}_{6}{ }^{\mathrm{a}, \mathrm{b}}$

\begin{tabular}{lllll}
\hline Atom & $\mathrm{O} 1$ & $\mathrm{O} 2$ & $\mathrm{O} 3$ & $\sum_{\text {cations }}$ \\
\hline $\mathrm{Pb}$ & $0.465+0.121+0.377$ & $0.248+0.159$ & $0.169+0.404$ & 1.943 \\
$\mathrm{Cu}$ & & $0.486^{[\times 2]}$ & $0.512^{[\times 2]}$ & 0.942 \\
$\mathrm{~B}$ & 0.958 & 1.022 & 2.027 \\
$\sum_{\text {anions }}$ & 1.921 & 1.915 & 2.922 \\
\hline
\end{tabular}

${ }^{\mathrm{a}}$ Bond valences calculated with the program Bond Valence Calculator Version 2.00, Hormillosa, C., Healy, S., Stephen, T. McMaster University (1993).

b Valence sums calculated with the formula: $S_{i}=\exp \left[\left(R_{0}-R_{i}\right) / B\right]$, where $S_{i}=$ valence of bond " $i$ " and $B=0.37$. Right superscripts indicate the number of equivalent bonds for cations.

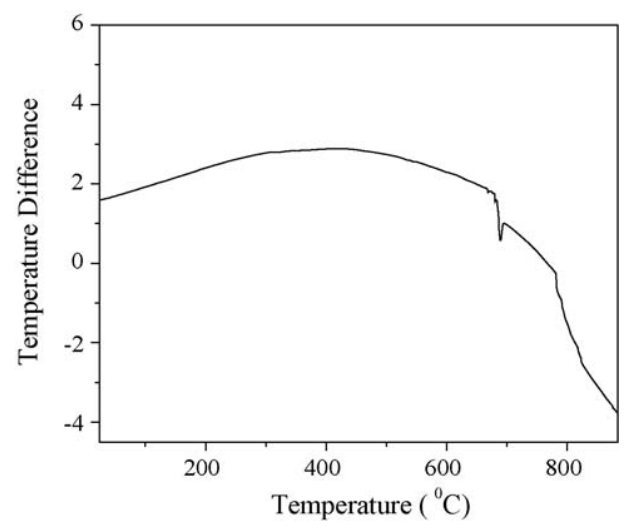

Fig. 3. The DTA of $\mathrm{Pb}_{2} \mathrm{CuB}_{2} \mathrm{O}_{6}$ compound.

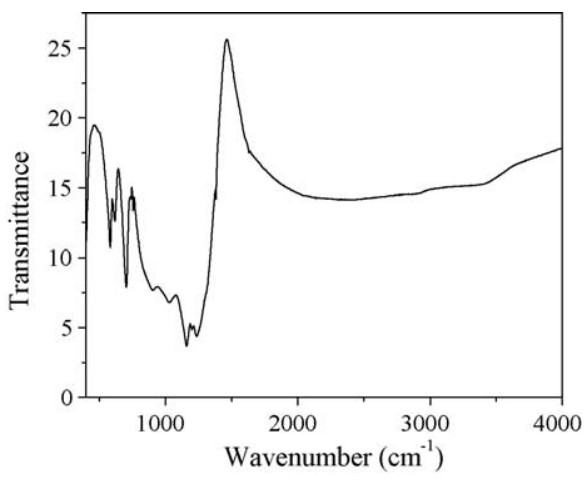

Fig. 4. The mid-infrared spectra of $\mathrm{Pb}_{2} \mathrm{CuB}_{2} \mathrm{O}_{6}$.

$C=0.3791 \mathrm{emu} \mathrm{K} / \mathrm{mol}$, and the Weiss constant, $\theta=-1.384 \mathrm{~K}$. The inset of Fig. 5 shows the linear temperature dependence of the reciprocal susceptibility, $\chi^{-1}(T)$, for $\mathrm{Pb}_{2} \mathrm{CuB}_{2} \mathrm{O}_{6}$ fitted to the Curie-Weiss law. Using the equation $C=N \mu_{\text {eff }}^{2} /\left(3 k_{\mathrm{B}}\right)$, the Curie-Weiss constant can be related to the effective magnetic moment, where $k_{\mathrm{B}}$ is the Boltzmann constant; $\mu_{\text {eff }}$ the effective magnetic moment (in Bohr magneton, $\mu_{\mathrm{B}}$, units), and $N$ is the number of magnetic atoms per unit sample mass. A value of $\mu_{\mathrm{eff}}=1.741 \mu_{\mathrm{B}}$ is obtained for the effective magnetic moment of $\mathrm{Cu}$ in $\mathrm{Pb}_{2} \mathrm{CuB}_{2} \mathrm{O}_{6}$ per formula unit from the equation $C=n \mu_{\text {eff }}^{2} /\left(3 k_{\mathrm{B}}\right)$. The experimental magnetic moment is in good agreement with the free-ion value of $\mathrm{Cu}^{2+}\left(3 \mathrm{~d}^{9}\right.$ configuration) according to $\mu_{\mathrm{eff}}=g[S(S+1)]^{1 / 2}=1.732$ with $g=2$ and $S=1 / 2$. 


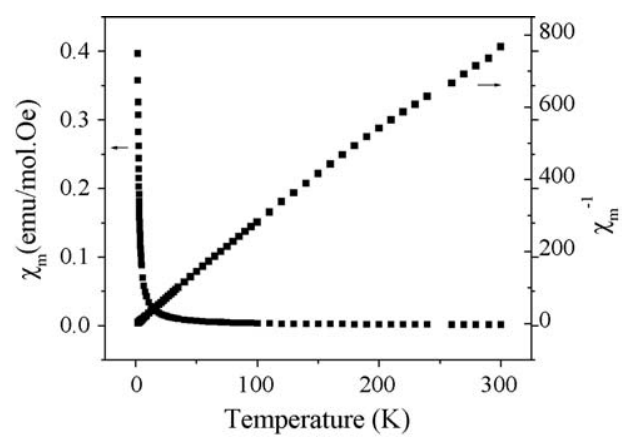

Fig. 5. Magnetic susceptibility and inverse susceptibility as a function of temperature for $\mathrm{Pb}_{2} \mathrm{CuB}_{2} \mathrm{O}_{6}$ under an applied magnetic field of 500 Oe.

The negative value for the Weiss constant $\theta=-1.384 \mathrm{~K}$ implies the possible existence of antiferromagnetism in the $\mathrm{Pb}_{2} \mathrm{CuB}_{2} \mathrm{O}_{6}$ sample at lower temperatures. Further susceptibility experimentation incorporating a dilution refrigerator would answer this question.

This material represents another in a series of copper containing borates, phosphates, and molybdates that have been investigated for their magnetic properties [14-16,33-35]. The magnetic properties can be easily modeled by Heisenberg magnetism (typically 1D chains and especially dimers). These materials have magnetic ordering transitions under $100 \mathrm{~K}$ (some are ferromagnetic [FM] and others are antiferromagnetic [AFM]) and they illuminate exchange interaction strengths and selection rules for how electrons choose exchange pathways.

Referring to Fig. 2b, the copper atoms constitute a rectangular 2D lattice when viewed along the $c$-axis and from Fig. 2c the copper atoms form a parallelogram 2D lattice when viewed along the $b$-axis. From these symmetries one would expect measurable magnetic ordering within the temperature range observed; however the 2D symmetry in Fig. 2a (when the crystal is viewed along the $a$-axis) is practically hexagonal. It is well known that hexagonal spin lattices are frustrated instead of anti-ferromagnetic and this observation (coupled with the negative tendency of the Weiss constant) may explain the lack of magnetic ordering at $T>2 \mathrm{~K}$.

$\mathrm{Pb}_{2} \mathrm{Cu}\left(\mathrm{BO}_{3}\right)_{2}$ is interesting because exchange and magnetic dipole interactions appear to completely cancel leaving essentially only paramagnetism. The absence of magnetic order might have interesting implications about the electron exchange integral in this class of compounds. Therefore this compound can serve as the 'zero' case for this class of materials and might link the AFM data to the FM data thus forming a complete model. Particularly, magnetic moment experiments at milli-Kelvin temperatures might observe an anti-ferromagnetic transition and the particular transition temperature would represent the relative spin exchange energies along the horizontal versus (two equivalent) diagonal directions in Fig. 2a. Should this happen to be the case, it would help explain how these materials decide whether to be FM or AFM.

\section{Conclusions}

$\mathrm{Pb}_{2} \mathrm{CuB}_{2} \mathrm{O}_{6}$ crystals have been grown successfully by slow cooling and the crystal structure has been determined. The main structural elements are sheets of isolated $\mathrm{CuO}_{4}$ square planes that are rotated out of the $b-c$ plane and connected by $\mathrm{BO}_{3}$ and $\mathrm{PbO}_{7}$ units. $\mathrm{Pb}_{2} \mathrm{CuB}_{2} \mathrm{O}_{6}$ is a congruently melting compound. The temperature dependences of the susceptibility shows that $\mathrm{Pb}_{2} \mathrm{CuB}_{2} \mathrm{O}_{6}$ exhibits paramagnetic behavior above $2 \mathrm{~K}$ and the $\chi-T$ curve fits the CurieWeiss law $\chi(T)=C /(T-\theta)$. The absence of magnetic ordering separates this compound from others with similar crystal chemistry and might serve to link ferromagnetism to antiferromagnetism in this class of materials.

\section{Acknowledgements}

We gratefully acknowledge the support from the National Science Foundation (Solid State Chemistry Award No. DMR-0312136), the EMSI program of the National Science Foundation at the Northwestern University Institute for Environmental Catalysis (Grant No. 9810378), and the Department of Energy, BES-Chemical Sciences, Geosciences, and Biosciences Division under grant No. DE-FG0203ER15457 for support of this work, and the use of the Central 
Facilities supported by the MRSEC program of the National Science Foundation (DMR-0076097) at the Materials Research Center of Northwestern University.

\section{References}

[1] Z. Hiroi, M. Azuma, M. Takano, Y. Bado, J. Solid State Chem. 95 (1991) 230.

[2] M. Azuma, Z. Hiroi, M. Takano, K. Ishida, Y. Kitaoka, Phys. Rev. Lett. 73 (1994) 3463.

[3] R.S. Eccleston, M. Uehara, J. Akimitsu, H. Eisaki, N. Motoyama, S.I. Uchida, Phys. Rev. Lett. 81 (1998) 1702.

[4] D.A. Vander Griend, S. Boudin, V. Caignaert, K.R. Poeppelmeier, Y. Wang, V.P. Dravid, M. Azuma, M. Takano, Z. Hu, J.D. Jorgensen, J. Am. Chem. Soc. 121 (1999) 4787.

[5] M. Azuma, T. Odaka, M. Takano, D.A. Vander Griend, K.R. Poeppelmeier, Y. Narumi, K. Kindo, Y. Mizuno, S. Maekawa, Phys. Rev. 62B (2000) R3588.

[6] H. Kageyama, K. Yoshimura, R. Stern, N.V. Mushnikov, K. Onizuka, M. Kato, K. Kosuge, C.P. Slichter, T. Goto, Y. Ueda, Phys. Rev. Lett. 82 (1999) 3168

[7] S. Miyahara, K. Ueda, Phys. Rev. Lett. 82 (1999) 3701.

[8] K. Kodama, M. Takigawa, M. Horvatic, C. Berthier, H. Kageyama, Y. Ueda, S. Miyahara, F. Becca, F. Mila, Science 298 (2000) 395.

[9] C. Chen, Y. Wu, A. Jiang, G. You, Sci. Sin. B7 (1984) 597.

[10] C. Chen, Y. Wu, A. Jiang, G. You, R. Li, S. Lin, J. Opt. Soc. Am. B6 (1989) 616.

[11] Y. Wu, T. Sasaki, S. Nakai, A. Yokotani, H. Tang, C. Chen, Appl. Phys. Lett. 62 (1993) 2614.

[12] L. Mei, C. Chen, B. Wu, J. Appl. Phys. 74 (1993) 7014.

[13] C. Chen, Y. Wang, B. Wu, K. Wu, W. Zeng, L. Yu, Nature 373 (1995) 322.

[14] Y. Mori, I. Kuroda, S. Nakajima, T. Saski, S. Nakai, Jpn. J. Appl. Phys. 34 (1995) 296.

[15] C. Chen, Y. Wang, Y. Xia, B. Wu, D. Dang, K. Wu, W. Zeng, L. Yu, J. Appl. Phys. 77 (1995) 2268.

[16] G. Aka, L. Block, J.M. Benitez, F. Salin, J. Godard, Eur. J. Solid State Inorg. Chem. 23 (1996) 727.

[17] M.I. Zargarova, N.M. Mustafaev, S.A. Mekhtieva, N.S. Shuster, Inorg. Mater. 33 (1997) 1235.

[18] SAINT-Plus, Version 6.02A; Bruker Analytical X-Ray Instruments Inc., Madison, WI, 2000.

[19] G.M. Sheldrick, SHELXTL, Version 6.14, Bruker Analytical X-ray Instruments Inc., Madison, WI, 2003.

[20] Bruker SMART Version 5.054, and SADABS Version 2.05, Bruker Analytical X-ray Systems Inc., Madison, WI, 2003.

[21] E.L. Belokoneva, Yu.K. Kabalov, A.G. Al-Ama, O.V. Dimitrova, V.S. Kurazhkovskaya, S.Yu. Stefanovich, Crystallogr. Rep. 47 (2002) 17.

[22] D.L. Corker, A.M. Glazer, Acta Crystallogr. 52B (1996) 260.

[23] R.W. Smith, D.A. Keszler, Acta Crystallogr. 46C (1990) 370.

[24] H. Behm, Acta Crystallogr. 38B (1982) 2781.

[25] H. Koenig, R. Hoppe, Z. Anorg. Allg. Chem. 434 (1977) 225.

[26] A. Vegas, F.H. Cano, S. Garcia-Blanco, Acta Crystallogr. 31B (1975) 1416.

[27] J. Pardo, M. Martinez-Ripoll, S. Garcia-Blanco, Acta Crystallogr. 30B (1974) 37.

[28] I.D. Brown, D. Altermatt, Acta Crystallogr. 41B (1985) 244.

[29] N.E. Brese, M. O’Keeffe, Acta Crystallogr. 47B (1991) 192.

[30] E.I. Kamitsos, M.A. Karakassides, G.D. Chryssikos, J. Phys. Chem. 91 (1987) 1073.

[31] Y. Jia, S. Gao, S. Xia, J. Li, Spectrochim. Acta 56A (2000) 1291.

[32] Z. Liu, L. Li, J. Li, M. Hu, J. Alloys Compd. 394 (2005) 277.

[33] A.A. Belik, M. Azuma, M. Takano, J. Magn. Magn. Mater. 272-276 (2004) 937.

[34] A.A. Belik, M. Azuma, M. Takano, Inorg. Chem. 42 (2003) 8572.

[35] Y. Qiu, C. Broholm, S. Ishiwata, M. Azuma, M. Takano, R. Bewley, W.J.L. Buyers, Phys. Rev. B 71(21) (2005) $214439 / 1$. 